\title{
OUTORGA ONEROSA DO DIREITO DE CONSTRUIR: ESTUDO DE CASO DO MUNICÍPIO DE SIDROLÂNDIA - MS
}

\section{ARTIGO ORIGINAL}

MACHADO, Edno Ribas ${ }^{1}$, SILVEIRA, Vítor Cardoso da²

MACHADO, Edno Ribas. SILVEIRA, Vítor Cardoso da. Outorga Onerosa do direito de construir: estudo de caso do município de Sidrolândia - MS. Revista Científica Multidisciplinar Núcleo do Conhecimento. Ano 06, Ed. 07, Vol. 12, pp. 4355. Julho de 2021. ISSN: 2448-0959, Link de acesso: https://www.nucleodoconhecimento.com.br/lei/municipio-de-sidrolandia, $\quad$ DOI: 10.32749/nucleodoconhecimento.com.br/lei/municipio-de-sidrolandia

\section{RESUMO}

O presente trabalho busca discutir a viabilidade da Outorga Onerosa do Direito de Construir através do estudo de caso estabelecido no Município de Sidrolândia MS que, com base na lei do Estatuto das Cidades, institucionalizou a mesma em sua Lei Orgânica Municipal e através dessa obteve recursos decorrentes da implantação de um loteamento, no qual foi estabelecido a Secretaria de Educação do Município, um auxílio para a reforma e manutenção da Escola Municipal "Porfíria Lopes do Nascimento", ação esta que economizou aos cofres públicos um valor estimado de $\mathrm{R} \$ 1.000 .000,00$, além de abrir precedentes futuros ao município, demonstrando os pontos positivos da Outorga Onerosa do Direito de Construir.

Palavras-chave: Estatuto das Cidades, Plano Diretor Municipal, Outorga Onerosa.

\footnotetext{
${ }^{1}$ Pós-graduado MBAA em Liderança e Coaching Gestão de Pessoas, Pós-graduação MBAA em Finanças e Controladoria, Tecnologia em Gestão Pública, graduado em Direito.

${ }^{2}$ Orientador.
}

RC: 92398

Disponível em: https://www.nucleodoconhecimento.com.br/lei/municipio-desidrolandia 


\section{INTRODUÇÃO}

A constituição de 1988 determinou que as cidades se tornaram entes federativos, que por lei adquiriram responsabilidades fundamentais na gestão dos municípios, uma vez que é delimitado pela união que quem mais tem ciência sobre os problemas locais são os próprios gestores que trabalham no município, a estes compreendem os problemas locais e são eles os próprios gestores que trabalham no município, pois convivem diariamente com as demandas e necessidades da população.

Assim sendo, são disponibilizados aos municípios ferramentas administrativas disponíveis no Estatuto das Cidades Lei ํo 10.257/2001 tais como as diretrizes para a elaboração do Plano diretor Municipal, no qual se delimita o uso e ocupação do solo.

Com os cortes de recursos oriundos dos repasses estaduais e federais, cabe aos municípios a administração desses recursos, o que gera a estes uma redução nos investimentos. Lidar com esta situação é um desafio grandioso aos gestores, fator este que justificou a realização deste trabalho.

Diante do contexto apresentado tem-se a seguinte questão de pesquisa: Qual a importância da criação da Lei de Outorga Onerosa para o município de Sidrolândia/MS? Este trabalho tem por objetivo apresentar a importância da criação a Lei de Outorga Onerosa para o município de Sidrolândia/MS expondo assim o caso positivo do município ao aderir à outorga onerosa em seu Plano Diretor Municipal.

Instituída pelo Estatuto das Cidades Lei Federal 10.257/01, por meio da qual as Prefeituras municipais concedem às incorporadoras o direito de usar o solo e parcelar mediante o pagamento de uma contrapartida financeira ao erário público.

De acordo com Silva (2000) a outorga onerosa do direito de construir regula e gera uma espécie de solo criado, um espaço edificável acima do coeficiente de

RC: 92398

Disponível em: https://www.nucleodoconhecimento.com.br/lei/municipio-desidrolandia 
aproveitamento estabelecido pelo plano diretor do municipal. Assim pode-se dizer que a elaboração desta lei foi desenvolvida com base nos princípios da solidariedade, justiça social e função social.

Para esta pesquisa foi utilizado o método de estudo de caso que contribui para compreender melhor os fenômenos individuais, os processos organizacionais e políticos da sociedade relacionados ao objeto da pesquisa.

A estrutura do presente artigo compor-se-á pelo referencial teórico sendo o primeiro tópico após esta introdução; o segundo tópico trata-se dos procedimentos metodológicos; o terceiro tópico é composto pela apresentação e análise dos resultados; e, conclui-se o presente trabalho com as considerações finais e referências bibliográficas.

\section{REFERENCIAL TEÓRICO}

O município de Sidrolândia está localizado a cem quilômetros da capital do Mato Grosso do Sul e teve seu desenvolvimento graças a três fatores fundamentais nos quais o desenvolvimento se acentuou ao decorrer dos anos, sendo a proximidade com a capital um desses fatores, outro fator está na localização por ser ponto de passagem da ferrovia Noroeste do Brasil que vinha de São Paulo até Campo Grande e o último fator é a agropecuária que se tornou a principal fonte de renda para o município.

O município de Sidrolândia-MS, vem crescendo consideravelmente, nos últimos 15 (quinze) anos sua população passou de cerca de 20.000 (vinte mil) habitantes para mais de 50.000 (cinquenta mil) habitantes, resultado do grande número de aldeias, assentamentos e dos investimentos em indústrias que criaram milhares de empregos e, consequentemente, atraiu milhares de famílias que se mudaram para esta cidade. Com o crescimento populacional, aumenta o desafio dos gestores em relação aos investimentos públicos uma vez que, administrar com recursos limitados diante de tantas demandas é realmente um grande problema para qualquer

Disponível em: https://www.nucleodoconhecimento.com.br/lei/municipio-desidrolandia 
especialista. Neste sentido, buscam-se alternativas, amparadas pela legalidade, para aumentar a receita do município e minimizar as deficiências orçamentárias. São instrumentos básicos da política urbana, determinados e regidos por Lei municipal, o Plano Diretor Municipal e o Planejamento Estratégico Municipal, sendo obrigatório para as cidades com mais de 20.000 habitantes a criação do Plano Diretor Municipal.

Antes de se definir o termo de outorga onerosa tem-se que entender os fatores que antecedem esta discussão, sendo relevante ressaltar que a mesma está inserida dentro dos limites da cidade.

A cidade é um bem difuso, entende-se assim que a mesma não é apenas o que nela é construído, mas também as pessoas e seu habitat, ressaltando a preocupação com as pessoas que nela moram, circulam e trabalham, voltando-se o olhar para a moradia, segurança, saúde, transporte e participação nas decisões públicas.

De acordo com Guerreiro Filho (2018), a cidade possui uma função social, que deve garantir o bem-estar de seus habitantes, disponibilizando a estes meios de ordenar o desenvolvimento social e espaciais para que estes tornem-se o melhor lugar possível para que se possa morar, trabalhar, estudar e viver.

O conceito de urbanismo está diretamente ligado ao conceito de cidade e os naturais necessidades conexas da civilização reunida em um mesmo espaço territorial. Determinar o significado de cidade não é tarefa fácil, eis que nem todo aglomerado urbano poderá ser assim considerado.

Para Silva (2015):

Cidade, no Brasil, é um núcleo urbano qualificado por um conjunto de sistemas político-administrativo, econômico não-agrícola, familiar e simbólico como sede do governo municipal, qualquer que seja sua população. A característica marcante da cidade no Brasil consiste no fato de ser um núcleo urbano, sede do governo municipal (SILVA, 2015, p. 26).

RC: 92398

Disponível em: https://www.nucleodoconhecimento.com.br/lei/municipio-desidrolandia 
Entende-se, portanto, que centros urbanos, ou cidade, estão diretamente ligados à ideia de sede do governo municipal, ou seja, no Brasil, a cidade é o agrupamento urbanístico onde está instituída a administração pública e o governo municipal.

A particularidade da cidade enquanto fenômeno a ser juridicamente regulado deu origem ao direito urbanístico, ramo do Direito dedicado às relações que envolvem a construção, a conservação e o uso dos espaços urbanos públicos e privados. São objetos do direito urbanístico, por exemplo, o parcelamento do solo, o zoneamento e as obras públicas (DI SARNO, 2004).

Nenhum dirigente político, investidor ou morador deve tomar decisões que envolvam o espaço construído sem levar em consideração as regras que organizam sua produção e seu uso. É preciso conhecer a situação fundiária e as restrições ambientais, urbanísticas e de preservação do patrimônio cultural que incidem sobre a área em questão (SANTIN; MARANGON, 2008).

O crescimento desordenado torna-se uma questão que deve ser considerada por todos os administradores públicos. Não há mais espaço para o descaso ou omissão, é necessário que os gestores estejam atentos às leis, para que as construções que compõem os núcleos urbanos, sejam ordenadas de forma a diminuir os gastos públicos e otimizar os investimentos com as necessidades básicas, como saúde, infraestrutura e educação.

De acordo com Maleronka (2010), o valor do direito de construir concedido pela legislação urbanística e as eventuais injustiças, decorrentes de disparidades dos coeficientes de acordo com o zoneamento. Assim pode-se dizer que a criação de solo é a criação de áreas adicionais de piso utilizável não apoiadas diretamente sobre o solo.

Ao se falar da criação do solo e salientar o direito de construir remete-se a Canotilho (1999) que afirma que a propriedade privada não possui legitimidade apenas ao título obtido, a essa deve-se conferir a função social que tem como objetivo conceder a mesma, legitimidade judicial tornando-a associativa e construtiva.

RC: 92398

Disponível em: https://www.nucleodoconhecimento.com.br/lei/municipio-desidrolandia 
Cada cidade possui suas variáveis e suas peculiaridades, assim ressalta-se que mesmo diante do Estatuto das cidades, o artigo primeiro da Lei ㄲo 10.257/2001 estabelece as normas de ordem pública e de interesse social que regulam o uso e a propriedade urbana em prol do bem coletivo, da segurança e do bem-estar dos cidadãos. As particularidades entre elas devem ser ressaltadas e levadas em consideração ao decorrer do processo de planejamento e desenvolvimento das mesmas, a isso se atribui o Plano diretor Municipal, que é um instrumento de planejamento municipal regido e orientado por esta lei federal, mas que é formado nas esferas municipais.

Realizado pela gestão pública municipal, o Plano diretor envolve diversas questões da sociedade, aspectos físicos, sociais e administrativos institucionais (SILVA, 2000). Enfatiza-se ainda que a elaboração deste está vinculada ao auxílio da sociedade (CORREA et al., 2010).

A elaboração do plano diretor municipal deve levar em consideração algumas regras estabelecidas pelo Estatuto das Cidades previsto na Lei 10.257/2001, tais como:

I. Parcelamento, edificações e utilização compulsória de imóveis; II. Direito de preempção;

III. Direito de outorga onerosa do direito de construir;

IV. Direito de alterar onerosamente o uso do solo;

V. Operações urbanas consorciadas;

VI. Direito de transferir o direito de construir.

Vale salientar que é dever do Poder Público demonstrar conexão com os conteúdos constituído no Estatuto da Cidade, desprezando comportamentos que objetivam simplesmente desmerecer dispositivos positivados, elencados no respeito à gestão democrática municipal, e aos instrumentos de política urbana da outorga onerosa e da transferência do direito de construir, previstos no Estatuto da Cidade (SANTIN; MARANGON, 2008). 
Ainda, o coeficiente de aproveitamento dos imóveis é determinado de maneira individual por cada Município, sendo este o responsável em delinear em seu perímetro territorial o coeficiente estabelecido. Com isso, a extensão do Município é deliberada em áreas, determinando os coeficientes mínimo, básico e máximo de proficuidade dos terrenos enaltecidos no Plano Diretor (VOITILLE, 2013).

O coeficiente mínimo está relacionado ao mínimo do espaço que pode ser edificável, respeitando o que está determinado naquela região, sem com isso desrespeitar o que é exigido na função social estabelecido pelo art. 5, parágrafo 1 , da Lei 10.257/2001. O coeficiente básico está relacionado ao percentual de área pela qual se pode construir sem que seja necessário ao proprietário efetuar pagamentos ao poder público. O coeficiente máximo estabelece o máximo da capacidade de construção que pode ser feita em determinada área e que não altere ou prejudique a qualidade de vida de seus habitantes (BRASIL, 2001).

Ainda, O Estatuto da Cidade apresenta no seu parágrafo $1^{\circ}$ do artigo 28 que, "coeficiente de aproveitamento é a relação entre a área edificável e a área do terreno". Desta maneira, calcula-se o percentual necessário de uma área para a construção de um prédio que apresenta determinada área construída. Com isso, o que ultrapassar o valor determinado pelo coeficiente básico e até o máximo estará deliberado como objeto da outorga onerosa do direito de construir (ACQUAVIVA, 2005).

Em relação ao que se refere a outorga onerosa do direito de construir esta baseia-se no direito de construir acima do limite do coeficiente de aproveitamento básico determinado pelo Plano Diretor municipal, através de pagamento efetuado aos cofres públicos, efetuado pelo beneficiário (FIORILLO, 2002).

De acordo com o caput do artigo 28 do Estatuto da Cidade, é determinado ao Plano Diretor definir "áreas nas quais o direito de construir poderá ser exercido acima do coeficiente de aproveitamento básico adotado, mediante contrapartida a ser prestada pelo beneficiário" (BRASIL, 2001). 
Por conseguinte, a outorga onerosa do direito de construir é um documento que possibilita avultar o direito de construir, fazendo com que o proprietário possa efetivar o direito de concretizar um maior coeficiente de aproveitamento básico determinado pelo Município naquela região.

A outorga onerosa do direito de construir é um processo integrado de organização da cidade, junto a outros instrumentos e institutos, todos sob a tutela de um ordenamento local, construído democraticamente, para o desenvolvimento de todas as áreas da cidade e a distribuição, o mais equitativa possível, dos benefícios e dos ônus produzidos pela urbanização, de modo a permitir o acesso de todos os ganhos produzidos pelo desenvolvimento da cidade, diluindo os ônus ocasionados pela aglomeração humana, de modo que não tenhamos no processo de urbanização mais um elemento fomentador da exclusão (GUERREIRO FILHO, 2018, p. 18).

As discussões referentes a outorga onerosa no Brasil iniciaram-se em 1975, onde estabelece-se que o direito de edificar acima de coeficiente só seria permitido quando ocorresse um pagamento ao poder público e que este direito poderia ser transferido.

Segundo Oliveira (2002), mesmo sendo regulamentada pelo estatuto das cidades a utilização da Outorga Onerosa de Direito de Construir deve ser definida por lei específica dos municípios, dependendo de cada gestão.

De acordo com Paz (2017, p. 7), a Outorga Onerosa do Direito de Construir é um instrumento implementado pela Lei Federal do Estatuto das Cidades em 2001, e implica uma parceria entre a Administração Pública e a iniciativa privada, onde há contrapartida financeira.

De igual forma afirmam Santi e Marangon (2008), a Outorga Onerosa do Direito de Construir, o direito de construir em área maior que o limite estabelecido pelo Plano Diretor, mediante contrapartida financeira aos cofres públicos a ser prestada pelo beneficiário.

O instrumento da outorga onerosa deve atender, portanto, a função social da propriedade, já que o poder sobre a propriedade é limitado pelo interesse coletivo,

Disponível em: https://www.nucleodoconhecimento.com.br/lei/municipio-desidrolandia 
definido por meio das normas urbanísticas, tais como códigos de obras, leis de parcelamento, leis de uso e ocupação do solo, normas ambientais (SANTIN; MARANGON, 2008).

Enaltecendo esse propósito, foram materializados a outorga e a transferência do direito de construir. No entanto, é fundamental que ocorra uma confirmação e regulamentação em âmbito municipal, pois dessa maneira, ainda que exista uma limitação da propriedade, os proprietários de imóveis tombados poderão lograr do benefício de poder transferir o potencial de construção daquele terreno para outro imóvel (DI SARNO, 2004).

Além disso, cabe a população o papel de coordenar, exigir, fazer valer as normas legais, para com o Poder Judiciário. Com isso, em situações de descumprimento, caberá aos agentes públicos a incumbência de uma ação civil pública, responsabilizando esses agentes dos danos causados ao meio ambiente, ao consumidor, a bens e direitos de valor artístico, estético, histórico, turístico e paisagístico (MALERONKA, 2010).

Para Gaidex e Schussel (2015, p. 25), existem regras do direito urbanístico que impõem restrições ao uso da propriedade e essas normas urbanísticas instalaram, no Brasil, uma discussão acerca da separação entre o direito da propriedade e o direito de construir.

Com isso, é evidente que a ação civil pública precisa acontecer em todas as situações que envolvam danos causados a tais valores, gerando assim uma ação cautelar para defesa da ordem urbanística, objetivando a busca pela aplicabilidade do princípio fundamental da dignidade da pessoa humana.

É válido salientar que de acordo com o ordenamento jurídico, em todas as situações que ocorrer o descumprimento do interesse público em relação da insolvência do titular na supremacia dos interesses econômicos e sociais da propriedade urbana, ainda que o direito ampare o interesse do proprietário do direito real de propriedade, a predileção será sempre a favor do interesse público.

RC: 92398

Disponível em: https://www.nucleodoconhecimento.com.br/lei/municipio-desidrolandia 


\section{PROCEDIMENTOS METODOLOGICOS}

Para a realização deste trabalho utilizou-se a metodologia de pesquisa bibliográfica, onde a fonte para a realização do mesmo foi o embasamento em livros, artigos de periódicos e materiais disponibilizados a internet.

Para Gil (2007, p. 44), os exemplos mais característicos desse tipo de pesquisa são sobre investigações sobre ideologias ou aquelas que se propõem à análise das diversas posições acerca de um problema.

Contudo o embasamento metodológico foi o de estudo de caso que se apresenta como um todo baseando-se em uma variedade de fontes de informação (GRESSLER, 2003). Este autor afirma que o estudo de caso é frequentemente utilizado em pesquisas exploratórias de áreas novas e assuntos sobre os quais ainda não existe uma base cientifica consolidada.

Segundo Yin (2001, p.32): "o estudo de caso é uma investigação empírica de um fenômeno contemporâneo dentro de um contexto da vida real, sendo que os limites entre o fenômeno e o contexto não estão claramente definidos". Yin (2001) enfatiza ser a estratégia mais escolhida quando é preciso responder a questões do tipo "como" e "por quê" e quando o pesquisador possui pouco controle sobre os eventos pesquisados.

Após o levantamento bibliográfico realizou-se visita in loco e entrevista com os gestores municipais quanto a aplicabilidade da Outorga Onerosa no Município de Sidrolândia (MS), assim como a utilização da mesma para auxiliar na arrecadação.

Foi realizada entrevista com o procurador jurídico do município Dr. Luiz Cláudio Palermo, responsável pela criação da lei municipal da Outorga Onerosa do Direito de Construir. Assim como membros do Legislativo Municipal e do poder Executivo. As entrevistas foram gravadas em aparelho celular, não ocorrendo transcrição de todo o conteúdo, utilizando-se apenas as informações pertinentes e os comentários dos entrevistados.

RC: 92398

Disponível em: https://www.nucleodoconhecimento.com.br/lei/municipio-desidrolandia 


\section{APRESENTAÇÃO E ANÁLISE DOS RESULTADOS}

A prefeitura municipal de Sidrolândia, através da sua controladoria jurídica, buscou a criação da lei, que prontamente fora apreciada e aprovada pelo legislativo, por entender a importância destes recursos para o benefício da população, principalmente nas necessidades primordiais que tangem a saúde, educação e infraestrutura. O município de Sidrolândia (MS) trouxe a previsão de legalizar o instrumento em seu último Plano Diretor, pela Lei Complementar 109/2015 no artigo 152, promulgada e regulamentada com a Lei Complementar 122/2017 específica de Uso e Ocupação do solo urbano e seu parcelamento impondo limitações à sua concessão.

A Câmara de Vereadores do município de Sidrolândia, através de suas comissões, analisou a proposta do executivo, na criação da Lei Municipal da Outorga Onerosa, e entendeu a necessidade da aprovação da mesma, após análise e discussão detalhada da lei.

O prefeito municipal, diante das dificuldades em conseguir recursos para investimentos importantes e básicos, viu na lei da outorga onerosa do direito de construir, a possibilidade de alocar recursos que possam ser aportados em necessidades mais urgentes como saúde e educação, dispensando, inclusive, as licitações.

Em entrevista com o Procurado Jurídico Dr. Claudio Palermo, teve-se a confirmação da importância da lei, uma vez que ele, autor da lei municipal da Outorga Onerosa do Direito de Construir, afirmou que o município necessita de reordenamento urbano e, paralelo a essa ação, também necessita de recursos para investimentos em vários setores, especialmente saúde e educação. O mesmo ainda teve o entendimento que a lei veio para preencher uma lacuna, que se remete a onde as empresas do setor imobiliário podem investir em contrapartida ao uso do solo nas áreas urbanas. A Outorga Onerosa do Direito de Construir, surge como um retorno 
imediato na aplicação dos recursos em setores estratégicos da administração pública.

Além da Lei Federal do Estatuto das Cidades e do Plano Diretor, entre outros incisos anteriormente citados, baseou-se também no rege a Lei Orgânica Municipal, Capítulo III - Da Competência do Município - Seção I - da Competência Privativa:

- 4ำ - A política de desenvolvimento urbano, que ordenará as funções sociais da cidade e da função social de utilização do espaço urbano, deverá garantir o bem estar social de seus habitantes, o direito do povo à utilização da cidade e dos próprios públicos, o parcelamento do solo, as edificações e funcionamento dos bens e serviços à disposição da sociedade, consubstanciada em Plano Diretor de Desenvolvimento Integrado, discutido com a sociedade, nos termos do art. 182, $\S 1^{\circ}$, da Constituição Federal, respeitada a vontade dos habitantes manifestada em assembleias e as peculiaridades do Município (Modificado pela Emenda à Lei Orgânica n. 001/2015).

Uma das vantagens do município ao aplicar o recurso da lei de outorga é, que conforme a Lei 866/93, não é necessário licitar mão de obra nem material, evitando custo operacional. Outra situação é que com o dinheiro em caixa a gestão pública tem maiores vantagens na negociação e consegue executar as ações em menor tempo.

A incorporadora poderia utilizar e parcelar o solo em determinadas áreas do município, quando autorizado pelo executivo, mediante à concessão da outorga onerosa. Os benefícios da Lei Municipal são diretamente ligados à população mais carente, uma vez que os recursos em pecúnias serão aplicados nos setores que mais necessitam.

No caso de Sidrolândia a aplicabilidade da mesma se deu por implantação e utilização do loteamento Vival dos Ipês no qual observou-se neste a aplicabilidade da lei sendo este repassado e investido na Secretaria de Educação, em específico na Escola Municipal "Porfíria Lopes do Nascimento" localizada no grande bairro São Bento, que recebeu em torno de 1 milhão de reais em obras de modernização, reforma e ampliação.

RC: 92398

Disponível em: https://www.nucleodoconhecimento.com.br/lei/municipio-desidrolandia 
A isso se corrobora a real eficiência e eficácia da utilização da outorga onerosa, sendo então a mesma passível de ser aplicada em outras situações uma vez que esta já se encontra estabelecida nas leis municipais e no plano diretor municipal. Sendo então utilizado um recurso que não estava nos cofres públicos e que não denotou custos ao município uma vez que este repasse vem de uma fonte externa a prevista nas leis de diretrizes orçamentarias. Contudo há que se ressaltar a real utilização deste recurso, processo este estabelecido por intermédio da fiscalização da população.

\section{CONSIDERAÇÕES FINAIS}

Conclui-se que a Lei, embora já existente na esfera federal, não existia no município e, ao ser criada por sugestão do departamento jurídico da prefeitura municipal, de imediato surtiu impactos positivos, uma vez que a arrecadação com a lei de outorga onerosa aplicada ao loteamento Vival dos Ipês, resultou na reforma da Escola Municipal Porfíria Lopes do Nascimento.

A ausência de uma bibliografia adequada para a realização desta pesquisa se fez como uma grande dificuldade encontrada, contudo a abordagem metodológica utilizada auxiliou muito no processo de construção deste artigo.

Uma vez estabelecida em lei orgânica a utilização da Outorga Onerosa vem a auxiliar o município com o investimento em áreas nas quais os recursos estaduais e federais são escassos. Demonstrar o sucesso da implantação deste caso é de suma importância para incentivar e divulgar demais municípios a investirem na implantação desta lei em seus planos diretores. Há, porém, de se ressaltar que, dependendo da situação, o mesmo pode acabar gerando uma especulação imobiliária com o encarecimento dos valores dos terrenos no caso de utilização deste processo com empresas do ramo imobiliário como neste caso.

Considerando o objetivo apresentado no início deste trabalho, pretende-se com o resultado desta pesquisa, compreender o comportamento das empresas 
investidoras no ramo imobiliário, observando o cumprimento da lei de uso e ocupação do solo. E acompanhar a aplicação dos recursos produtos da lei da outorga onerosa, feita pelo município, de forma fiscalizatória e indicativa, onde o maior beneficiário deve ser, sem sombra de dúvida, a população carente do município.

\section{REFERÊNCIAS}

ACQUAVIVA, Marcus Cláudio. Vademecum Universitário de Direito. 8. ed. rev. ampl. São Paulo: Editora Jurídica Brasileira 2005.

BRASIL. Lei no 10.257, de 10 de julho de 2001: regulamenta os arts. 182 e 183 da

Constituição Federal, estabelece diretrizes gerais da política urbana e dá outras providências.

Disponível

em: http://www.planalto.gov.br/ccivil_03/leis/leis_2001//10257.htm. Acesso em: junho de 2019.

CANOTILHO, José Joaquim Gomes. Direito constitucional. 3. ed. Coimbra: Livraria Almedina, 1999.

CORRÊA, C. C.; LISTON, R. F.; BARBOS, A. C.; SILVA, C. P.; BARCZSZ, S. S. Gestão Pública e Desenvolvimento Sustentável: A Importância da Implantação de Plano Diretor no Ato de Criação de um Município. Sociedade Brasileira de Economia, Administração e Sociologia Rural. Tecnologia, desenvolvimento e integração social. 48 ${ }^{\circ}$ Congresso. Campo Grande. 2010. Disponível em: <http://www.sober.org.br/palestra/15/954.pdf>. Acesso em 10 de julho de 2019.

DI SARNO, Daniela Campos Libório. Elementos de direito urbanístico. São Paulo: Manole, 2004. 
FILHO, Evaldo José Guerreiro. A Outorga Onerosa e o Direito de Construir: da Política Urbana na Constituição Federal à Outorga Onerosa do Direito de Construir no Município de Ipema/SC. Editora Lumen Juris. Rio de Janeiro, 2018.

FIORILLO, Celso Antonio Pacheco. Estatuto da Cidade Comentado: lei 10.257/2001: lei do meio ambiente artificial. São Paulo: Editora Revista dos Tribunais: 2002.

GAIDEX, Raquel de Barros; SCHUSSEL Zulma. Outorga onerosa do direito de construir e a transferência do direito de construir: instrumento de política urbana para proteção do patrimônio histórico cultura. Pontifícia Universidade Católica do $\begin{array}{lllll}\text { Paraná } & - & \text { PR } & 2015 . & \text { Dsponível }\end{array}$ $<w w w . r e v i s t a s . u s p . b r / r i s c o / a r t i c l e / d o w n l o a d / 121392 / 118304>$. Acesso em 29 de julho de 2019.

GIL, A. C. Como Elaborar Projetos de Pesquisa. São Paulo: Editora Atlas, 2001.

GRESSLER, Lori Alice. Introdução à Pesquisa, Projetos e Relatórios. São Paulo: Loyola, 2003.

MALERONKA, Camila. Projeto e gestão na metrópole contemporânea: Um estudo sobre as potencialidades do instrumento 'operação urbana consorciada' à luz da experiência paulistana. São Paulo: FAUUSP, 2010. Tese apresentada à Faculdade de Arquitetura e Urbanismo da Universidade de São Paulo para obtenção do título de doutor em Arquitetura e Urbanismo. Disponível em: file:///D:/Downloads/CamilaMaleronka_tese.pdf. Acesso em: junho de 2019.

MEIRELLES, Hely Lopes. Direito administrativo brasileiro. 39. ed. São Paulo: Malheiros, 2013. 925 p.

MORAES, Alexandre de. Direitos Humanos Fundamentais: teoria geral, comentários aos art. $1^{\circ}$ a $5^{\circ}$ da Constituição da República Federativa do Brasil, doutrina e jurisprudência. 5. ed. São Paulo: Atlas, 2003. 
OLIVEIRA, Regis Fernandes de. Comentários ao estatuto da cidade. São Paulo: Editora Revista dos Tribunais, 2002.

PAZ, Thaís Yane Kegler. A aplicação da Outorga Onerosa do Direito de construir: o caso da cidade de Palmas - TO. XVII Enanpur. São Paulo, 2017. Disponível em:< http://ampur.org.br/xviienanpur/principal/publicacoes/xviienanpur_anais/st_sessoes_t ematic as/st3.4/st3.4-02.pdf>. Acesso em 29 de julho de 2019.

PINHO, Evangelina; BRUNO FILHO, Fernando Guilherme; MATTOS, Liana Portilho (Org). Estatuto da cidade. Belo Horizonte: Mandamentos, 2002.

SANTIN, Janaína Rigo; MARANGON, Elizete Gonçalves. O estatuto da cidade e os instrumentos de política urbana para proteção do patrimônio histórico: outorga onerosa e transferência do direito de construir. História vol.27 no.2 Franca 2008. Disponível em: http://www.scielo.br/scielo.php?script=sci_arttext\&pid=s010190742008000200006. Acesso em: 15 de junho de 2019.

SILVA, J. A. Direito urbanístico brasileiro. São Paulo: Malheiros, 2000.

SOUZA, Marcelo Lopes de. Mudar a cidade: uma introdução crítica ao planejamento e à gestão urbanos. 2. ed. Rio de Janeiro: Bertrand Brasil, 2003.

VOITILLE, Nadine. O Estatuto da Cidade, 2013. Disponível em: https://www.cliquearquitetura.com.br/artigo/o-estatuto-da-cidade.html. Acesso em: junho de 2019.

Enviado: Julho, 2021.

Aprovado: Julho, 2021. 